\title{
Familial episodic pain syndrome: a case report and literature review
}

\author{
Pingping Zhang ${ }^{1 \#}$, Feng Xiao ${ }^{2 \#}$, Xiaofeng Li ${ }^{1}$, Ying Liang ${ }^{1}$, Huan Yi $^{1}$, Minghui Hou ${ }^{1}$, Yikun Mou ${ }^{1}$, \\ Zhuanggui Chen ${ }^{1}$
}

${ }^{1}$ Department of Pediatrics, The Third Affiliated Hospital of Sun Yat-sen University, Guangzhou, China; ${ }^{2}$ Department of Stomatology, The Third Affiliated Hospital of Sun Yat-sen University, Guangzhou, China

\#These authors contributed equally to this work.

Correspondence to: Yikun Mou; Zhuanggui Chen. Department of Pediatrics, The Third Affiliated Hospital of Sun Yat-sen University, Guangzhou 510630, China. Email: myk66321@163.com; chenzhuanggui@126.com.

\begin{abstract}
The purpose of this case report and literature review is to show that familial episodic pain syndrome (FEPS) is a non-inflammatory genetically inherited pain syndrome. A 3-year-old boy presented at our hospital with pain in both his forearms and lower limbs below the knees for more than 3 years. There were no abnormalities in the blood tests, blood smears, liver and kidney function tests, trace elements tests, cellular immunity test, humoral immunity test, autoantibody tests, C-reactive protein (CRP) test, erythrocyte sedimentation rate (ESR) test, and tumor-related and bone marrow cytology examinations. Additionally, the imaging examination results showed no abnormalities. From the patient's medical history, we found that the mother of the child had a family history of a similar disease. To date, only 21 cases of FEPS 3 caused by the sodium voltage-gated channel alpha subunit 11A (SCN11A) gene mutation have been reported. Although the age of onset is different, most of them are inherited in families. The results of the genetic examination revealed that the pain mainly came from the genetic inheritance of the maternal family line. The whole exon gene test revealed that the pain was caused by 2 heterozygous mutations of c.674G $>\mathrm{T}$ and c.671T $>\mathrm{C}$ in the SCN11A gene.
\end{abstract}

Keywords: Familial episodic pain syndrome (FEPS); genetic inheritance; sodium voltage-gated channel alpha subunit 11A (SCN11A); heterozygous mutation; case report

Submitted Nov 08, 2021. Accepted for publication Jan 27, 2022.

doi: $10.21037 /$ atm-22-102

View this article at: https://dx.doi.org/10.21037/atm-22-102

\section{Introduction}

Familial episodic pain syndrome (FEPS) refers to a group of paroxysmal non-inflammatory pain syndromes that mainly involve the distal extremities (1). Based on the discovery time of the pathogenic gene, FEPSs are divided into 3 types: (I) FEPS1 (2) caused by the transient receptor potential cation channel (TRPA1) gene mutation; (II) FEPS2 (3) caused by the sodium voltage-gated channel alpha subunit 10A (SCN10A) gene mutation; (III) FEPS3 (4) caused by the sodium voltage-gated channel alpha subunit $11 \mathrm{~A}$ (SCN11A) gene mutation. Among them, FEPS3 is a very rare nerve ion channel disease $(3,5)$. The FEPS3- induced disease usually attacks from infancy, and mainly manifests as episodic pain in the distal limbs. However, due to insufficient expression in infants and young children, the probability of early detection of the disease is small (6). As this disease usually occurs at night, infants and young children often cry at night. Existing reports have revealed that this disease is mainly heredity, and that as the patient's age increases, the pain gradually decreases or even disappears. There are more treatment methods for ion channel diseases than other rare diseases. The male child in this article presented at our hospital with pain in both forearms and lower limbs below the knees for more than 3 years. No abnormalities were found in the routine 


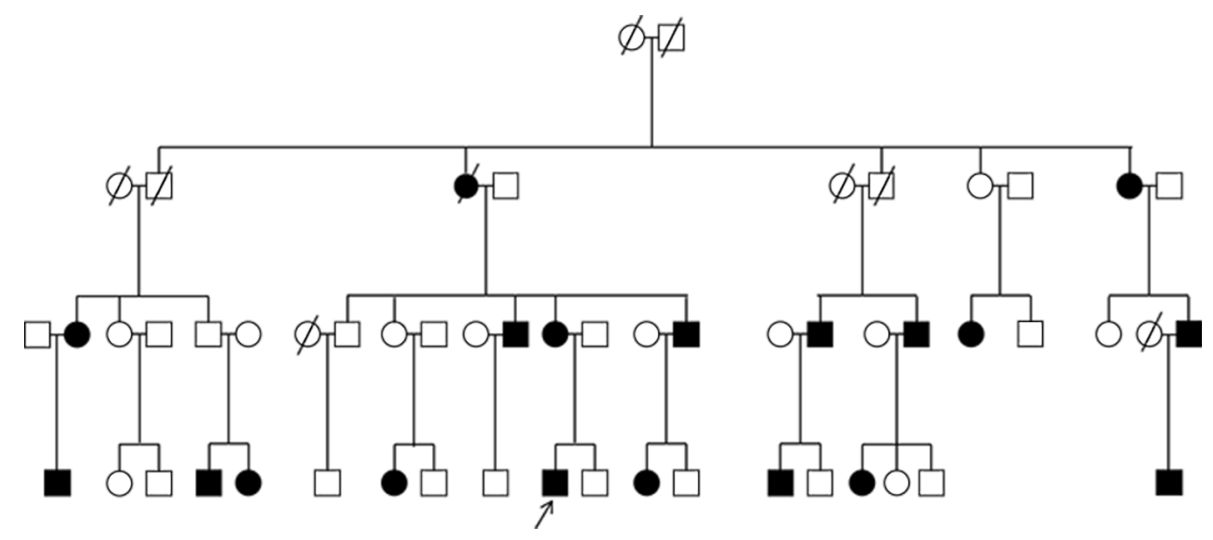

Figure 1 Family diagram. The arrow indicates the proband; the disease has appeared in the family for 5 consecutive generations, and has an autosomal dominant inheritance pattern. Oblique lines inserted in the circle and square: male or female death from this disease. Circle: female; square: male.

examination results. Later, by asking his family medical history, the pain was found to be genetically inherited from his mother's family. In this study, through wholeexome gene testing, the pain of the patients in the family was found to be caused by 2 heterozygous mutations in the SCN11A gene of c.674G > T and c.671T > C. Notably, the c. $671 \mathrm{~T}>\mathrm{C}$ mutations had not been previously reported. We present the following article in accordance with the CARE reporting checklist (available at https://atm. amegroups.com/article/view/10.21037/atm-22-102/rc).

\section{Case presentation}

All procedures performed in this study were in accordance with the ethical standards of the institutional and/or national research committee(s) and with the Helsinki Declaration (as revised in 2013). Written informed consent was obtained from the patients' guardians of the patient for publication of this case report and accompanying images. A copy of the written consent is available for review by the editorial office of this journal.

A male patient aged 3 years and 9 months old presented at our hospital with pain in both forearms and lower limbs below the knees for more than 3 years. The patient had cried frequently since childhood, and since he had begun to talk, he had often complained of limb pain, mostly in both his forearms, calves, knee joints, and feet. The attacks usually occurred at night. There was no obvious predisposing factor. The episodes occurred 2-3 days apart, and the pain occurred either during or before sleep, lasted about 30-60 min each time, and affected his sleep quality.
Treatments such as massage and warmth did not relieve the pain. After tiring from crying, the child was generally able fall asleep for about 1 hour or until a pain attack occurred again. This pattern generally repeated several times, and the sweating of the child increased, until the second day, when the pain disappeared. During the intermittent period, the limbs of the patient were roughly normal, with no limitations of movement, no fever, and no joint swelling.

Six months ago, the patient attended a local hospital and was given targeted treatments such as calcium supplementation, Singulair, Keratin anti-allergic, Parvin, and Voltaren ointment, but showed little improvement. The child has had poor sleep quality since childhood and awakens easily. From the onset of the illness, the child began getting thinner, and has a poor nutritional status; however, his development in the areas of sports and intelligence are similar that of children of the same age. The diet of the patient is normal, and there was no dysfunction in his urine or feces, no history of other special diseases, and no history of exposure to special drugs or poisons.

Family medical history: The child's parents were not close relatives. Nineteen family members from the children mother's family had experienced similar symptoms for 3 consecutive generations (see Figure 1). The child's mother was 37 years old and had also experienced paroxysmal limb pain from childhood to 20 years of age when the episodes reduced. The mother still experiences pain occasionally, but with less frequency and same degree. The mother now experiences pain attacks 2 to 3 times per year, for about 10 minutes, and then experiences relief. The patient himself described experiencing severe pain during the onset period, 

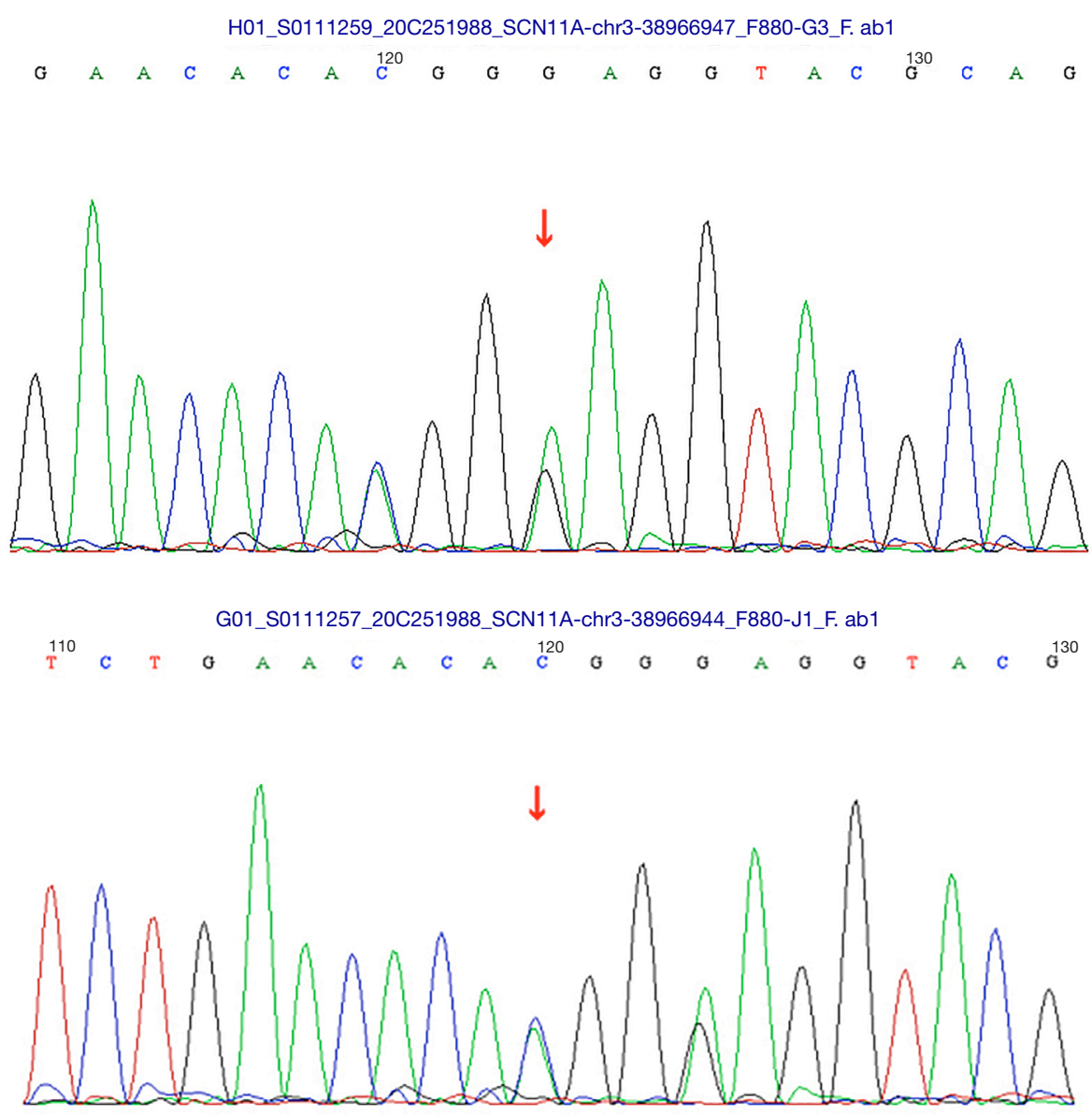

Figure 2 Family sequencing results. The arrow indicates the mutation site.

accompanied by excessive sweating. An uncle and cousin of the patient and some other family members had experienced limb pain since childhood similar to that of the patient and his mother. The pain usually gradually decreased from the ages of 20 and 30 years old and occurred with less frequency.

Examination results: The patient's vital signs were stable, and no obvious abnormalities were observed in the physical examination. There were no abnormalities in the blood tests, blood smears, liver and kidney function tests, trace elements test, cellular immunity test, humoral immunity test, autoantibody tests, C-reactive protein (CRP) test, erythrocyte sedimentation rate (ESR) test, and tumor-related and bone marrow cytology examinations. Additionally, the imaging examination results showed no abnormalities. The residual imaging examination results were generally normal, except for a small amount of fluid in the bilateral ankle joints and bilateral knee joints. The patient's medical history revealed that the mother of the child had a family history of a similar disease. The family sequencing results are shown in Figure 2.

Genetic examination results: Second-generation sequencing revealed 2 heterozygous mutations in the SCN11A gene of c.674G > T and c.671T > C (see Table 1). The family sequencing results showed that family members with the same symptoms all had the mutations, but family members without any symptoms were wild-type, suggesting that the genotype and phenotype were co-segregating in the family. The c.674G > T mutation in the SCN11A protein changed the 225th amino acid from arginine to leucine (p.R225L) (7), and the c.671T > C mutation in the SCN11A protein changed the 224th amino acid from phenylalanine to serine (p.F224S). It has previously been reported that the split hand/foot malformation-related mutation occurs in the p.R225L site (7), but three have been no reports on this mutation in the p.F $224 \mathrm{~S}$ site. 
Databases were searched using the following keywords: "familial episodic pain syndrome." Four articles related to SCN11A gene mutations and FEPS3 families were retrieved $(6,8-10)$. The 4 articles reported on 50 families. Kabata et al. (6) reported on 42 families, but only 4 families were reported on in detail, Zhou et al. (8) reported on 1 family, Okuda et al. (9) reported on 6 families, and Leipold et al. (10) reported on 1 family (see Table 2).

\section{Discussion}

FEPS refers to a group of paroxysmal non-inflammatory pain syndromes that mainly involve the distal extremities. Its pathogenic mechanism is mainly related to the mutation of ion channel genes in dorsal root ganglion neurons (11). FEPSs are divided into 3 types, among which SCN11A is the core subunit of the NaV1.9 sodium channel. FEPS3 is a very rare type of nerve ion channel disease (9). Indeed, to date, only about 20 FEPS3 families have been reported on worldwide (9). In the first list of 121 rare diseases in China, cardiac ion channel disease and congenital myotonia are also related to ion channel gene mutations. However, the number of patients with these 2 types of diseases is far greater than that of patients with FEPS3 caused by the SCN11A mutation.

Generally, the onset of FEPS3 occurs in infancy, and the disease manifests as episodic pain in the distal limbs. At present, there is no specific drug for the treatment of familial paroxysmal pain syndrome. The main treatment is to use painkillers to reduce pain symptoms, and pay attention to keep warm and avoid cold environment (12). As infants and young children cannot express themselves well, early diagnosis of the disease is difficult (13). However, the clinical onset of FEPS 3 in children follows a certain pattern (14): cold, fatigue, hunger, and the rainy season are the predisposing factors for most children with FEPS3; pain mostly occurs in the afternoon or at night; paroxysmal pain lasts for tens of minutes and then relieves, and then starts again after a short interval, and repeat several times, resulting in "tandem" painful episodes; some children experience increased sweating of their limbs during the episodes. Thus, when infants and young children cry severely for unknown reasons, if some of the aforementioned characteristics are observed, the possibility of episodic pain syndrome should be considered. The crying should not be ignored, and it should not be assumed that the child has a functional disease or psychological illness.

In this study, when the patient was admitted to hospital, 
Table 2 Literature review of FEPS3

\begin{tabular}{|c|c|c|c|c|c|}
\hline $\begin{array}{l}\text { Serial } \\
\text { number }\end{array}$ & $\begin{array}{l}\text { Proband } \\
\text { gender }\end{array}$ & Onset time & Painful area & Mutation type & $\begin{array}{l}\text { Inherited from } \\
\text { father/mother }\end{array}$ \\
\hline 1 & Male & Between 2-3 years old & $\begin{array}{l}\text { Lower limbs and upper limbs usually occurs } \\
\text { on the forearm, upper arm, thigh and calf area }\end{array}$ & p.F814C & Mother (6) \\
\hline 2 & Male & Infancy & $\begin{array}{l}\text { Elbows, toes, knees, and occasionally on the } \\
\text { forearms }\end{array}$ & p.F1146S & Father (6) \\
\hline 4 & Female & 1 year old & $\begin{array}{l}\text { Lower limbs and upper limbs usually occurs } \\
\text { on the fingers, toes, and knees }\end{array}$ & p.V1184A & Mother (6) \\
\hline 5 & Female & 8 months & $\begin{array}{l}\text { Elbows, wrists, knees, and ankles, and } \\
\text { radiates to the distal limbs }\end{array}$ & p.R222H & Father (8) \\
\hline 8 & Male & Infancy & Pain in limbs and migraine & p.R222S & Mother (9) \\
\hline 9 & Male & Infancy & Paroxysmal limb pain & p.R222H & Father (9) \\
\hline 10 & Female & Infancy & Paroxysmal limb pain & p.R222H & Father (9) \\
\hline 11 & Male & Infancy & Paroxysmal limb pain & p.R222H & Mother (9) \\
\hline 12 & Female & 1 year old & $\begin{array}{l}\text { Starts at the joints, and radiates to the } \\
\text { arms and legs }\end{array}$ & p.V1184A & Father (10) \\
\hline
\end{tabular}

FEPS3, familial episodic pain syndrome 3.

no abnormalities were found in the routine blood tests, blood smears, liver and kidney function tests, trace elements test, cellular immunity test, humoral immunity test, autoantibody tests, CRP test, ESR test, and tumor-related and bone marrow cytology examinations. Consequently, secondary limb pain diseases, such as rheumatic myalgia, thrombocythemia, myeloproliferative disorders, and arthritis, were basically excluded. In view of the clear family history of autosomal dominant inheritance, we first considered a diagnosis of erythematous limb pain associated with ion channel disease (15), but during the literature search, we learned that of another type of disease named "familial episodic pain syndrome". There is only 1 family report of TRPA1-related FEPS1, and its clinical onset is similar to that of FEPS3, but the pain is mostly distributed in the upper part of the body, and it is accompanied by more autonomic symptoms (2). There is also only 1 family report of SCN10A-related FEPS2, and its clinical symptoms are almost the same as FEPS3, but its onset mostly starts in adulthood (8). In addition to being related to FEPS3, SCN11A is also related to congenital insensitivity to pain (16), acute pruritus (17), painful peripheral neuropathy (13), postoperative hyperalgesia syndrome (18), and small fiber neuropathy (19). The peripheral neuropathology results of the father of the proband showed severe small fiber nerve loss, suggesting that FEPS3 patients may have small fiber neuropathy at the late stage.

FEPS 3 episodes in patients gradually diminish and eventually disappear with age. Most patients get better at the beginning of puberty, and it is rare that patients over 40 years old experience this pain (15-17). Patients from the same family show similar disease processes. The mother, uncle, and cousin of the patient all had similar episodes with pain. The pain usually gradually relieved from the ages of 20 and 30 in these adults, and occurred with less frequency. The comparative analysis of the genetic sequencing results of the child and his mother also proved that this type of pain was mainly due to a genetic inheritance from the maternal family line.

Mutations in the SCN11A gene can lead to a variety of clinical phenotypes due to the variation of amino acid positions in different domains, which can lead to the loss or gain of function of sodium channels (20-22). The SCN11A protein is composed of 4 transmembrane domains, each 
of which has 6 transmembrane segments, of which the 4th segment is the core voltage-sensing domain. After every 3 amino acids, there is a positively charged amino acid (Arginine $\mathrm{R}$ or Lysine $\mathrm{K}$ ). This domain is highly conserved in all human sodium channel $\alpha$ subunits $(20,23)$. Through whole-exome gene testing, the pain of the patients in the family was found to be caused by 2 heterozygous mutations in the SCN11A gene of c.674G > T and c.671T > C. Notably, the c.671T > C mutations had not been previously reported.

Limb pain is a common clinical symptom in neurology. In most patients, limb pain is often accompanied by local injury or inflammation, or a clear systemic disease, and thus the cause is relatively easy to determine. However, when patients do not present with these symptoms and signs, the diagnosis of limb pain can sometimes become difficult. Further, some patients have psychological abnormalities, which are usually mistaken for "non-organic diseases".

This paper reported on a rare patient for which limb pain was the main manifestation. A number of possible causes of pain were considered. Pain is a defensive response that elicits subjective feelings. Its essence is a manifestation of abnormal electrical excitability. When primary limb pain occurs, clinicians should start from the anatomical basis of the pain occurrence and conduction, pay attention to the etiology of peripheral receptors, ion channels, small fiber nerves, etc., make corresponding analyses and generalizations and obtain a family disease history.

\section{Acknowledgments}

Funding: This study was supported by the Major Collaborative Research of the People's Livelihood Technology Innovation Project in Guangzhou (No. 201704020179), the Natural Science Foundation of Guangdong Province (No. 2019A1515011441), and Guangdong Medical Science and Technology Research Foundation (No. A2021386).

\section{Footnote}

Reporting Checklist: The authors have completed the CARE reporting checklist. Available at https://atm.amegroups. com/article/view/10.21037/atm-22-102/rc

Conflicts of Interest: All authors have completed the ICMJE uniform disclosure form (available at https://atm. amegroups.com/article/view/10.21037/atm-22-102/coif).
The authors have no conflicts of interest to declare.

Ethical Statement: The authors are accountable for all aspects of the work in ensuring that questions related to the accuracy or integrity of any part of the work are appropriately investigated and resolved. All procedures performed in this study were in accordance with the ethical standards of the institutional and/or national research committee(s) and with the Helsinki Declaration (as revised in 2013). Written informed consent was obtained from the patients' guardians of the patient for publication of this case report and accompanying images. A copy of the written consent is available for review by the editorial office of this journal.

Open Access Statement: This is an Open Access article distributed in accordance with the Creative Commons Attribution-NonCommercial-NoDerivs 4.0 International License (CC BY-NC-ND 4.0), which permits the noncommercial replication and distribution of the article with the strict proviso that no changes or edits are made and the original work is properly cited (including links to both the formal publication through the relevant DOI and the license). See: https://creativecommons.org/licenses/by-nc-nd/4.0/.

\section{References}

1. Packiasabapathy S, Sadhasivam S. Gender, genetics, and analgesia: understanding the differences in response to pain relief. J Pain Res 2018;11:2729-39.

2. Kremeyer B, Lopera F, Cox JJ, et al. A gain-of-function mutation in TRPA1 causes familial episodic pain syndrome. Neuron 2010;66:671-80.

3. Han C, Yang Y, Te Morsche RH, et al. Familial gain-offunction Nav1.9 mutation in a painful channelopathy. J Neurol Neurosurg Psychiatry 2017;88:233-40.

4. Zhang XY, Wen J, Yang W, et al. Gain-of-function mutations in SCN11A cause familial episodic pain. Am J Hum Genet 2013;93:957-66.

5. Zhou X, Xiao Z, Xu Y, et al. Electrophysiological and Pharmacological Analyses of Nav1.9 Voltage-Gated Sodium Channel by Establishing a Heterologous Expression System. Front Pharmacol 2017;8:852.

6. Kabata R, Okuda H, Noguchi A, et al. Familial episodic limb pain in kindreds with novel Nav1.9 mutations. PLoS One 2018; 13:e0208516.

7. Carter TC, Sicko RJ, Kay DM, et al. Copy-number variants and candidate gene mutations in isolated split 
hand/foot malformation. J Hum Genet 2017;62:877-84.

8. Zhou BB, Zhu M, Hong DJ. Adolescent women with paroxysmal pain in extremities for 15 years-familial paroxysmal pain syndrome. Chinese Journal of Nervous and Mental Diseases 2020;46:60-3.

9. Okuda H, Noguchi A, Kobayashi H, et al. Infantile Pain Episodes Associated with Novel Nav1.9 Mutations in Familial Episodic Pain Syndrome in Japanese Families. PLoS One 2016;11:e0154827.

10. Leipold E, Hanson-Kahn A, Frick M, et al. Coldaggravated pain in humans caused by a hyperactive $\mathrm{NaV} 1.9$ channel mutant. Nat Commun 2015;6:10049.

11. Palada V, Kaunisto MA, Kalso E. Genetics and genomics in postoperative pain and analgesia. Curr Opin Anaesthesiol 2018;31:569-74.

12. Zhou BB, Zhu M, Hong DJ. Adolescent female with episodic pain in extremities for 15 years - familial episodic pain syndrome. Chinese Journal of Nervous and Mental Diseases 2020;46:121-4.

13. Huang J, Estacion M, Zhao P, et al. A Novel Gain-ofFunction Nav1.9 Mutation in a Child With Episodic Pain. Front Neurosci 2019;13:918.

14. Zhou X, Xiao Z, Xu Y, et al. Electrophysiological analyses of mutants of the human voltage-gated sodium channel NAv1.9 that cause pain disorders by establishing a heterologous expression system. Toxicon 2019;158:S57.

15. Klein-Weigel PF, Volz TS, Richter JG. Erythromelalgia.

Cite this article as: Zhang $\mathrm{P}, \mathrm{Xiao} \mathrm{F}, \mathrm{Li} \mathrm{X}$, Liang Y, Yi H, Hou M, Mou Y, Chen Z. Familial episodic pain syndrome: a case report and literature review. Ann Transl Med 2022;10(4):238. doi: 10.21037/atm-22-102
Vasa 2018;47:91-7.

16. King MK, Leipold E, Goehringer JM, et al. Pain insensitivity: distal S6-segment mutations in NaV1.9 emerge as critical hotspot. Neurogenetics 2017;18:179-81.

17. Salvatierra J, Diaz-Bustamante M, Meixiong J, et al. A disease mutation reveals a role for $\mathrm{NaV} 1.9$ in acute itch. J Clin Invest 2018;128:5434-47.

18. Sun J, Duan G, Li N, et al. SCN11A variants may influence postoperative pain sensitivity after gynecological surgery in Chinese Han female patients. Medicine (Baltimore) 2017;96:e8149.

19. Lauria G, Merkies IS, Faber CG. Small fibre neuropathy. Curr Opin Neurol 2012;25:542-9.

20. Lolignier S, Bonnet C, Gaudioso C, et al. The Nav1.9 channel is a key determinant of cold pain sensation and cold allodynia. Cell Rep 2015;11:1067-78.

21. Noguchi A, Takahashi T, Okuda H, et al. Paroxysmal limb intolerable pain (infantile pain episodes associated with novel Nav1.9 mutations in familial episodic pain syndrome). Nihon Rinsho 2017;75:641-51.

22. Gabrion A, Hmitou I, Moshous D, et al. Gain-of-Function Mutation. Retour Au Numéro, 2017.

23. Spillane J, Kullmann DM, Hanna MG. Genetic neurological channelopathies: molecular genetics and clinical phenotypes. J Neurol Neurosurg Psychiatry 2016;87:37-48. 